\title{
Arteriohepatic dysplasia
}

\section{Familial pulmonary arterial stenosis with neonatal liver disease}

\author{
G. H. WATSON and V. MILLER \\ From the Royal Manchester Children's Hospital, St. Mary's Hospital, and \\ the University Department of Child Health, Manchester
}

\begin{abstract}
Watson, G. H., and Miller, V. (1973). Archives of Disease in Childhood, 48, 459. Arteriohepatic dysplasia: familial pulmonary arterial stenosis with neonatal liver disease. A new syndrome is described of which the salient features are (1) congenital hypoplasia and stenoses of the pulmonary arteries, sometimes with associated cardiovascular malformations; (2) neonatal liver disease, commonly with obstructive jaundice and resembling biliary atresia or neonatal hepatitis, but sometimes apparent only as mild persistent hepatic dysfunction; and (3) various minor congenital anomalies, including an odd facies. There is a familial tendency suggesting autosomal dominant inheritance, with variable penetrance.
\end{abstract}

The purpose of this article is to describe a new syndrome with a familial tendency. The chief manifestations are pulmonary arterial hypoplasia or stenoses, neonatal liver disease usually with obstructive jaundice clinically suggesting neonatal hepatitis or intrahepatic biliary atresia, and some minor skeletal and other features.

\section{Clinical details}

Five families are reported with 21 children. Of these children, 5 seemed normal, 11 had liver involvement, and 14 had cardiovascular abnormalities; thus 9 had both. Of the 14 children with cardiovascular abnormalities, 12 had evidence of pulmonary arterial stenoses which were shown in 9 by arteriography, in 1 by necropsy, and in 2 more were suspected on strong clinical grounds; 1 stillborn child had a truncus arteriosus; and in 1 child the diagnosis is unknown. No adults underwent a full cardiac investigation, but one parent in each of 3 of the families had strong clinical evidence of pulmonary arterial stenosis and a fourth had suggestive signs, all 4 having consulted cardiologists in the past. The family trees for the 5 families are shown in Fig. 1.

The 5 families appeared to be unrelated; in 4 the parents were English, while in family $S$ the father was Polish and the mother Italian. There was no parental consanguinity.

Biochemical investigations were performed by routine methods. Levels of serum $5^{\prime}$-nucleotidase (said to be more specific than alkaline phosphatase in hepatobiliary disease) were estimated by the method of Persijn et al. (1968), the usual normal adult levels

Received 20 October 1972. falling within the range of 2 to 17 units/1., most being below 11 units/1., and children having lower levels. Cardiac catheterizations were carried out at the Royal Manchester Children's Hospital by standard methods.

The significant cardiological findings and liver function tests in all the affected children are summarized in Tables I and II, respectively, and the pedigrees are shown in Fig. 1. Fig. 2 shows pulmonary arteriograms on single frames of $16 \mathrm{~mm}$ cineangiograms, Fig. 2a being a normal example.

\section{Children.}

\section{Case reports}

Case B II.1. Jaundice from soon after birth for 10 weeks, clinically suggesting 'neonatal hepatitis'. At age 16 months was symptomless though rather small, and liver felt normal, but had abnormal liver function tests. Grade 3/4 systolic murmur in left 2nd intercostal space and over lungs. Investigations showed pulmonary artery hypoplasia and stenoses (Fig. 2b).

Case M II.1. Jaundice from second day of life for 4 months clinically suggesting 'neonatal hepatitis'. Grade 2/4 systolic murmur noted at birth. No present evidence of liver disease except abnormal liver function lests. Cardiac investigations showed pulmonary arterial hypoplasia and stenoses (Fig 2c).

Case M II.2.* 38-weeks stillborn girl with truncus arteriosus; liver normal at necropsy.

Case M II.3. Variable but at times severe obstructive jaundice from birth. Referred here at age 9 months with palpable liver, jaundice, some evidence of rickets, and hypercholesterolaemia. Needle liver biopsy sug-

\footnotetext{
^Cases not seen by us.
} 
(a) Family B

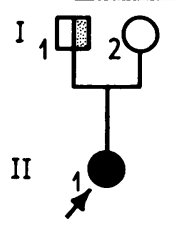

(d) Family $R$

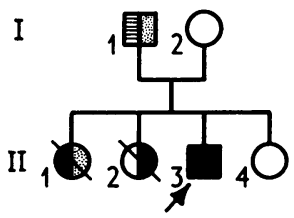

(b) Fomily $M$

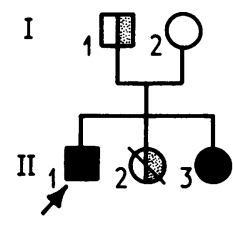

(c) Fomily N

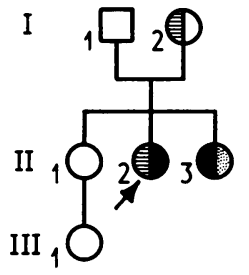

(e) Fomily $S$

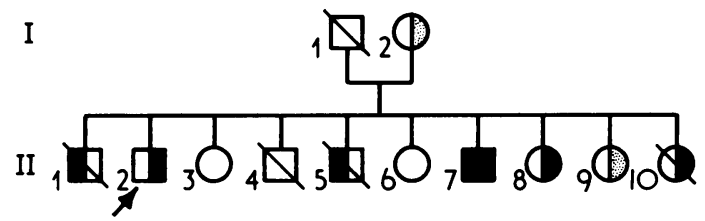

Demonstrable pulmonary artery stenoses 10 Other evidence of liver
dysfunction
Other evidence of $C V$ abnormality
$D$ Prolonged neonatal obstructive jaundice

FIG. 1.-Family trees, pedigree charts of families $B, M, N, R$, and $S$

gested intrahepatic biliary atresia. Grade 2-3/4 systolic murmur in left 2nd intercostal space, well heard over lungs, and first noticed in infancy. Cardiac investigation showed pulmonary arterial stenoses and a secundum atrial septal defect with pulmonary/systemic flow ratio of $2 / 1$.

Case N II.1. Normal physical examination and liver function tests.

Case N III.1. Normal on physical examination.

Case $N$ II.2. Grade 2/4 systolic murmur in 2nd left intercostal space; investigation at age 10 showed mild right pulmonary artery stenoses (Fig. 2d). No history or signs of liver disease except for generalized pruritus present since early infancy; now, at age 20 years, has abnormal liver function tests but normal liver biopsy.

Case $N$ II.3. Referred at age 7 months because of variable obstructive jaundice from third day of life, severe at times now only mild. Liver enlarged, not firm. Laparotomy and cholangiography at age 7 months: normal gall bladder, all bile ducts present and patent, but lumen very small. Liver biopsy: some fibrosis, rudimentary bile ducts, suggestive of hypoplasia of biliary ducts. Much troubled by pruritus and hypercholesterolaemic xanthomata, much improved on cholestyramine. Grade $3 / 4$ systolic murmur at left 2 nd intercostal space and, grade 2, over lungs. ECG showed right ventricular enlargement; chest $x$-ray uninformative. Cardiac investigations refused.

TABLE I

Cardiovascular anomalies shown at investigation or necropsy

\begin{tabular}{|c|c|c|c|c|}
\hline Case no. & $\begin{array}{l}\text { Age } \\
(y \mathbf{r})\end{array}$ & $\begin{array}{l}\text { Pulmonary } \\
\text { artery stenoses }\end{array}$ & Other cardiovascular abnormality & $\begin{array}{l}\text { Right ventricular } \\
\text { pressure }(\mathrm{mmHg})\end{array}$ \\
\hline $\begin{array}{l}\text { B II.1 } \\
\text { M II.1 } \\
\text { M II.2 } \\
\text { M II.3 } \\
\text { N II.2 } \\
\text { R II.2 } \\
\text { R II.3 } \\
\text { S II.2 } \\
\text { S II.7 } \\
\text { S II.8 } \\
\text { S II.10 }\end{array}$ & $\begin{array}{l}11 \mathrm{mth} \\
5 \frac{1}{2} \\
\text { Stillborn } \\
2 \frac{1}{8} \\
8 \\
2 \frac{9}{1} \\
1 \frac{1}{2} \\
9 \frac{1}{2} \\
3 \frac{8}{2} \\
2 \frac{1}{2} \\
2 \mathrm{mth}\end{array}$ & $\begin{array}{l}+ \\
+ \\
? \\
+ \\
+ \\
+ \\
+ \\
+ \\
+ \\
+ \\
+\end{array}$ & $\begin{array}{l}\text { Truncus } \\
\text { Secundum atrial septal defect } \\
\text { Secundum atrial septal defect } \\
0 \\
0 \\
\text { Small left common carotid artery } \\
\text { Severe valvular pulmonary stenosis; small } \\
\text { left common carotid artery } \\
\text { Valvular pulmonary stenosis }\end{array}$ & $\begin{array}{l}70 / 4 \\
68 / 0 \\
48 / 4 \\
44 / 2 \\
- \\
45 / 3 \\
50 / 5 \\
65 / 5 \\
130 / 4 \\
70 / 2\end{array}$ \\
\hline
\end{tabular}



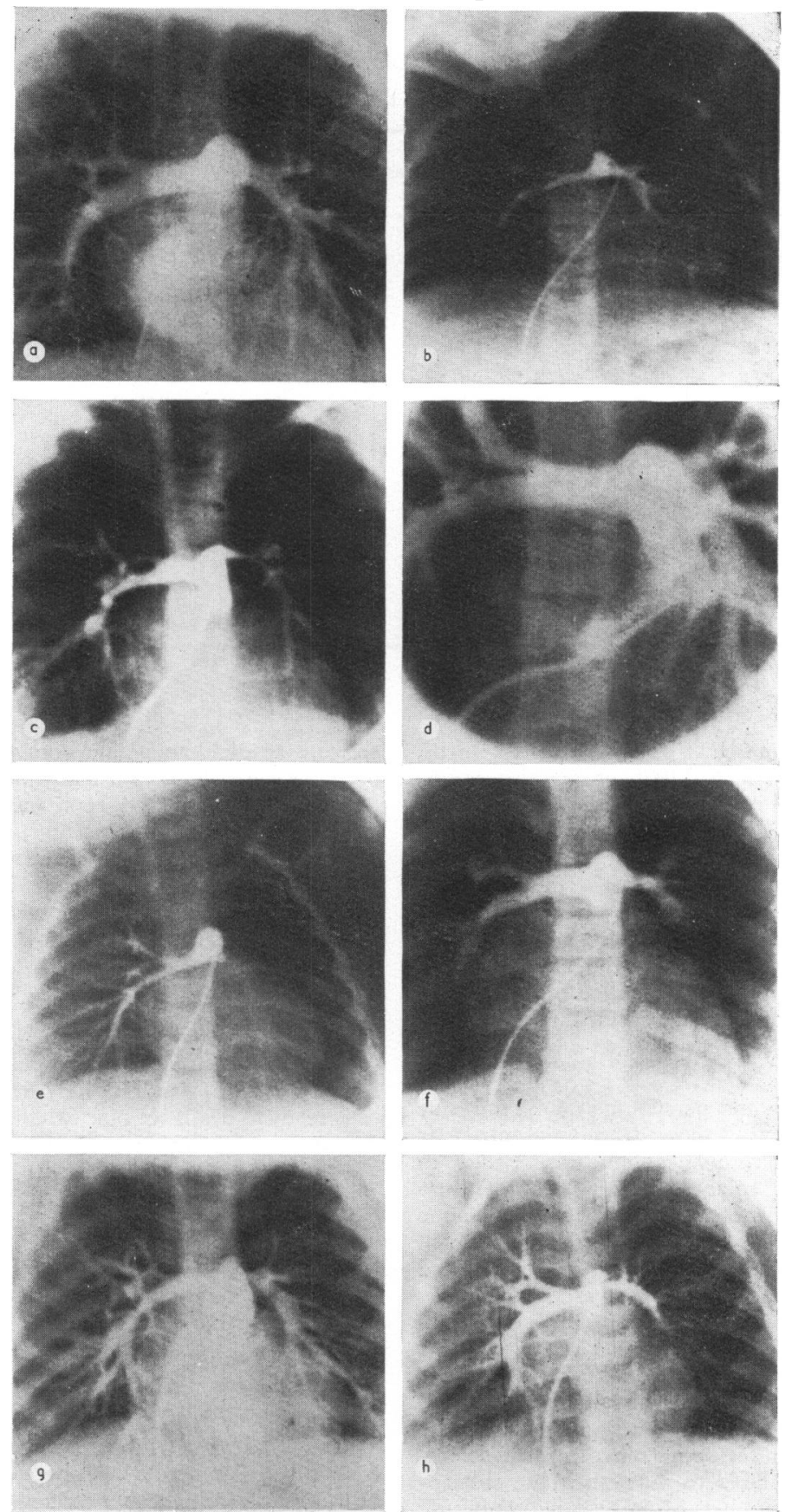

Fig. 2.-Pulmonary arteriograms. (a) Normal example for comparison; (b) Case B II.1, hypoplasia of MPA and RPA, and some stenosis in LPA; (c) Case M II.1, small LPA with trifurcation stenosis, stenosis in secondary branches of RPA, post-stenotic dilatation; (d) Case $N$ II.2, some stenosis at origin of right upper lobe $P A$ and in right lower lobe PA; (e) Case $R$ II.3, hypoplasia of RPA and main branches, and of LPA of which the origin is just visible; (f) Case $S$ II.2, small LPA with some stenosis at trifurcation, mild stenosis in right lower lobe $P A ;(g) C a s e S I I .7$, stenoses at origin of LPA and of right lower lobe PA, with post-stenotic dilatation; (h) Case S II.8, hypoplasia of MPA and stenosis at origin of $L P A$; slight stenoses at origin of $R P A$ and of some smaller branches. (MPA,RPA, and LPA $=$ main, right, and left pulmonary arteries.) 
TABLE II

Liver function tests in affected children

\begin{tabular}{|c|c|c|c|c|c|c|c|}
\hline Case no. & Age & $\begin{array}{l}\text { Total bilirubin } \\
\text { (mg/100 ml) }\end{array}$ & $\begin{array}{c}\text { Alkaline phosphatase } \\
\text { (KA units) }\end{array}$ & $\begin{array}{c}5^{\prime}-\text { Nucleotidase } \\
(\mathrm{mU} / \mathrm{ml})\end{array}$ & $\begin{array}{c}\text { SGOT } \\
\text { (units/ml) }\end{array}$ & $\begin{array}{c}\text { SGPT } \\
\text { (units/ml) }\end{array}$ & $\begin{array}{l}\text { Cholesterol } \\
(\mathrm{mg} / 100 \mathrm{ml})\end{array}$ \\
\hline $\begin{array}{l}\text { B II.1 } \\
\text { M II.1 } \\
\text { M II.3 } \\
\text { N II.2 } \\
\text { N II.3 } \\
\text { R II.1 } \\
\text { R II.2 } \\
\text { R II.3 } \\
\text { S II.5 } \\
\text { S II.7 }\end{array}$ & $\begin{array}{l}10 \mathrm{wk} \\
12 \mathrm{mth} \\
16 \mathrm{mth} \\
2 \mathrm{mth} \\
5 \frac{\mathrm{yr}}{} \\
13 \mathrm{mth} \\
2 \frac{\mathrm{yr}}{2} \\
20 \mathrm{yr} \\
7 \mathrm{mth} \\
1 \frac{1}{8} \mathrm{yr} \\
5 \frac{\mathrm{yr}}{2} \\
2 \mathrm{mth} \\
3 \mathrm{yr} \\
2 \mathrm{yr} \\
6 \mathrm{wk} \\
19 \mathrm{mth} \\
2 \mathrm{wk} \\
4 \mathrm{mth} \\
9 \mathrm{mth}\end{array}$ & $\begin{array}{r}2 \cdot 5 \\
3 \cdot 3 \\
2 \cdot 0 \\
6 \cdot 4 \\
<1 \\
20 \\
18 \\
<1 \\
2 \cdot 6 \\
3 \cdot 2 \\
4 \cdot 5 \\
9 \cdot 5 \\
38 \\
0 \cdot 6 \\
8 \cdot 8 \\
0 \cdot 5 \\
17 \\
3 \cdot 5 \\
0 \cdot 3\end{array}$ & $\begin{array}{c}69 \\
190 \\
52 \\
33 \\
26 \\
61 \\
81 \\
29 \\
54 \\
225 \\
112 \\
40 \\
42 \\
57 \rightarrow 32 \\
52 \\
48 \\
14 \\
20\end{array}$ & $\begin{array}{l}610 \\
75,79 \\
410 \\
69 \\
\end{array}$ & $\begin{array}{r}50 \\
240 \\
62 \\
154 \\
20 \\
320 \\
100 \\
34 \\
160 \\
420 \\
220 \\
330 \\
122 \\
23 \\
126 \\
54 \\
430 \\
181 \\
\end{array}$ & $\begin{array}{r}30 \\
240 \\
62 \\
290 \\
22 \\
300 \\
85 \\
50 \\
190 \\
450 \\
205 \\
280 \\
136 \\
15 \\
105 \\
84 \\
210 \\
270\end{array}$ & $\begin{array}{c}1360 \\
2000 \\
\\
220 \\
465 \\
960 \\
220 \\
1450 \\
2150 \\
338^{\star} \\
240 \\
260 \\
195 \\
410 \\
340\end{array}$ \\
\hline
\end{tabular}

^On cholestyramine.

Case $R$ II.1.* Jaundice from soon after birth, becoming progressively deeper with obstructive symptoms. Liver enlarged $3 \mathrm{~cm}$, becoming impalpable later. Laparotomy at age 10 weeks and again at 14 weeks: gall bladder and common bile duct patent, but hepatic ducts not found, nor visualized on cholangiography with common duct clamped. Liver biopsy at age 10 weeks: appearances suggested obstruction; empty medium-sized ducts seen in portal areas. Biopsy at age 14 weeks: bile plugs in canaliculae; ducts not now seen in portal areas. Systolic murmur noted, but no cardiological investigations carried out. Died at age $2 \frac{1}{2}$ years; no necropsy.

Case $R$ II.2.* Harsh and persisting systolic murmur noted in infancy; ECG showed right ventricular enlargement but no cardiological studies. Failed to thrive; liver noted to be enlarged. Extensive investigation negative; no malabsorption. A raised alkaline phosphatase was noted, which fell after additional vitamin $D$, but no other evidence of rickets. Died unexpectedly of pneumonia at age $2 \frac{3}{4}$ years. Necropsy (viscera available to us) showed secundum atrial septal defect; right ventricle dilated and also hypertrophied; distal pulmonary artery stenoses due to constrictions, largely at bifurcations, walls being histologically normal. Liver normal macroscopically and microscopically. Kidneys normal except for some narrowing of cortex, and some increase, confined to the immediate subcapsular region, in the number of immature glomeruli. System arteries in all available viscera normal.

Case $R$ II.3. Jaundice from third day of life for 2 months. Failure to thrive; extensive investigations in second year of life, including jejunal biopsy and

$\star$ Cases not seen by us. enzyme studies, and laparotomy, failed to explain his proven steatorrhoea and abnormal liver function tests. Steatorrhoea improved spontaneously. Liver biopsy: normal on light microscopy; electron microscopy showed many electron-dense microsomal bodies of unknown nature within the hepatocytes; otherwise normal. Grade 2/4 systolic murmur heard widely over the lungs; investigation showed pulmonary artery hypoplasia (Fig. 2e).

Case $R$ II.4. History and physical examination normal; no biochemical tests.

Case $S$ II.1.* Said to have had progressive jaundice from birth until death at age 4 months. Death certificate records death as due to congenital obliteration of bile ducts. No other documentation available.

Case $S$ II.2. Murmur noted at routine examination at 7 years of age. No cardiac or liver symptoms. Cardiac catheterization showed pulmonary arterial hypoplasia (Fig. 2f). No hepatic investigations.

Case $S$ II.3. History and physical examination normal. No biochemical tests.

Case S II.4.* Well until cot death at age 4 months. Coroner's necropsy showed no evidence of hepatic or cardiac abnormality.

Case $S$ II.5.* Admitted elsewhere with jaundice from third day of life. White stools noted, with heavy bilirubinuria and serum bilirubin of $17 \mathrm{mg} / 100 \mathrm{ml}$. Died at age 2 weeks after choking while being fed. At necropsy heart was recorded as normal; 'probe could not be passed through bile ducts'. No histology available.

Case $S$ II.6. History and physical examination normal. No biochemical tests. 
Case S II.7. Admitted elsewhere because of jaundice from first few days of life lasting for 5 months, with abnormal liver function tests and clinically suggesting 'neonatal hepatitis'. Grade 2-3/4 systolic murmur heard at this time over upper sternum and over lungs. Investigation later showed pulmonary arterial hypoplasia (Fig. 2g).

Case $S$ II.8. Jaundice for only a few days after birth, ? significance. No other significant symptoms; liver function not investigated. Grade 4/4 systolic murmur; cardiac investigation showed valvular pulmonary stenosis and pulmonary arterial hypoplasia (Fig. $2 \mathrm{~h}$ ).

Case S II.9. No symptoms Grade 2/4 systolic murmur at left 2nd intercostal space and over lungs. No other investigations permitted.

Case $S$ II.10. Slight dyspnoea on feeding. No liver symptoms. Grade 3/4 systolic murmur in left 2nd intercostal space and over lungs; investigations showed valvular pulmonary stenosis and pulmonary arterial hypoplasia. Died unexpectedly elsewhere, aged 4 months, from gastroenteritis; necropsy refused.

Parents. All parents were seen, and all examined by us except for S I.1, who died aged 47 from a gastric carcinoma. Except as noted, there were no relevant findings in their history or on examination; none had significant symptoms.

Case B I.1. 'Heart murmur' found at age 11 years. Broad skull, prominent ears. Grade 2/4 systolic murmur maximal in left second intercostal space but well heard over left upper lobe. Normal chest $x$-ray and ECG. Brother said to have died of congenital heart disease at age 3 years.

Case M I.1. 'Heart lesion' found in infancy. Thin build, round dorsal kyphos, large prominent ears, flat top of head, long prominent chin, irregular teeth. Grade $3 / 4$ systolic murmur across upper sternum and well heard over both lungs Chest $x$-ray-nil of note; ECG-rsR' pattern in VI.

Case $N$ I.2. Close facial resemblance to her two affected children. Some telangiectases; no murmurs. $5^{\prime}$-Nucleotidase higher than is uisual.

Case $R$ I.1. 'Heart murmur' found at age 3 years. Right ventricular impulse, grade $3 / 4$ systolic murmur across upper sternum and well heard over lungs. Chest $x$-ray uninformative; ECG-mild right ventricular enlargement. High 5'-nucleotidase.

Case S I.2. 'Heart murmur' said to have been found at age 4 years. Mother, and mother's sister, said to have had congenital heart lesions Grade 2/4 systolic murmur maximal in second left intercostal space and well heard across upper chest and over lungs. Chest $x$-ray and ECG uninformative.

Liver function tests were carried out on all parents except S I.1 and S I.2, and were normal except in Case N I.2 where 5'-nucleotidase levels, on separate occasions, were 22.5 and $15.8 \mathrm{mU} / \mathrm{ml}$; and in Case R I.1 : alkaline phosphatase $17 \mathrm{KA}$ units and $5^{\prime}$-nucleotidase $39 \mathrm{mU} / \mathrm{ml}$.

Parental blood cholesterol levels ranged between 200 to $300 \mathrm{mg} / 100 \mathrm{ml}$.

\section{Special features}

Birthweights. Of the 14 affected children born alive at term, none weighed over $3.2 \mathrm{~kg}$ and 5 weighed $2.72 \mathrm{~kg}$ or less at birth; while of the 5 apparently normal children, 3 weighed over $3.4 \mathrm{~kg}$ and only one weighed as little as $2 \cdot 72 \mathrm{~kg}$. A similar low birthweight has been noted in cases of neonatal hepatitis (Danks and Bodian, 1963) and is also present in most of the other children seen at this centre with idiopathic or familial pulmonary arterial stenoses.

Size. All the affected children were small and most were thin, only 2 being above the 15 th centile for height and weight, but 4 of the apparently unaffected children were also small. Affected and unaffected parents were of low normal height.

Physical features. The affected members tended to have rather odd facies, with some similarities between families. The facies tended to be rather flat, with rather high, wide cheek bones (though in family S Polish blood might account for this), and sometimes with a prominent forehead and prominent chin. Ears were malformed in R II.3, and prominent in 5 other cases. Some of these features could be recognized in the apparently affected parent, especially in families $M, R$, and $S$. The eyes were in general rather deep set and the extremities were normal; no one had the prominent eyes and stubby fingers noted in cases of cholestasis by Juberg et al. (1966) and Hirooka and Ohno (1968). 2 children (R II.3 and S II.2) had ectopic testes, and one parent (M I.1) had a round dorsal kyphos.

Skin. 6 children with liver involvement had palmar erythema, but none had 'spider naevi', though multiple small telangiectases were present on the face and trunk, especially along the costal margins, of two parents (M I.1 and R I.1) and on the face of a third (N I.2). A few were also present in Cases R II.2 and R II.3, who also had very dry scaly skin not present in the other families.

Mentality. All the children and parents were of normal intelligence, but Case S I.2 has had intermittent psychiatric treatment for a litigious psychopathic personality.

Skeletal anomalies. Complete skeletal surveys were not performed, but the following anomalies were discovered. (a) Large bilateral parietal 
foramina (Case R II.3), (b) bony bar connecting two ribs (Case B II.1), (c) upper tibial exostosis (Case R I.1), (d) persistent double centres to one vertebra (Cases N II.2 and S II.7), (e) fusion of adjacent vertebrae (Case $\mathrm{N}$ II.2), (f) marked 'butterfly-wing' vertebrae (Case B II.1).

These features have not been encountered in any of the other children seen because of pulmonary arterial stenoses, and are not typical of the postrubella syndrome.

Blood pressure. Labile systolic hypertension without other clinical evidence of renal or vascular disease seemed unduly common in apparently affected parents, the unaffected parents having normal pressures (except for N I.1 with 160/100 $\mathrm{mmHg}$ at age 54). The range of blood pressure recordings was as follows. $M I .1$ at 34 and 42 years of age, 165/60,160/70; N I.2 at 46 and 51 years, $160 / 70,130 / 65 ; B I .1$ at 27 and 28 years, 130/70, 200/90; R I.1 at 15 and 28 years, 150/70, 160/70; S I.2 at 36 and 38 years, 190/80, 140/80. No parents had clinical signs of peripheral systemic arterial stenosis.

Pyelograms. Postangiographic and other pyelograms were available for 10 of the affected children, and were all normal, but in 4 the pelvis was bifid and the calyces long and narrow.

Other investigations. The following investigations gave negative or normal results when performed on one or more of the affected children in each family except $S$ : chromosome analysis; tests for rubella, cytomegalovirus, and toxoplasma infection, and for $\mathrm{Au}$ antigen and antibody; serum electrolytes, calcium, phosphorus, and blood urea; $\alpha-1$ antitrypsin and immunoglobulin levels; sweat tests (R II.2 and R II.3 only); WR (negative in all mothers also). Blood counts and urine examination, including amino acid chromatography, were normal except for some changes attributable to severe hepatic disease. Plasma protein levels and electrophoresis showed no striking changes. Detailed examination of blood groups (ABO only in family S) showed no unusual pattern.

Right hepatic vein wedge pressures and wedge venograms were normal in Cases B II.1, M II.1, M II.3, and R II.3.

\section{Discussion}

Pulmonary arterial hypoplasia and stenosis. Except in severe cyanotic cardiac malformations with pulmonary oligaemia, of which a small pulmonary arterial tree can be regarded as a part, pulmonary arterial hypoplasia or stenosis was regarded for many years as a rare necropsy finding. It was not diagnosed in life until 1953, but many cases have been reported since then. Maternal rubella and, less frequently, infantile hypercalcaemia are well-recognized factors, and in others a familial incidence is not infrequent, with either clear dominant inheritance or sib involvement only, suggesting recessive inheritance. The diagnosis can be suspected on clinical grounds, especially by the presence of a systolic murmur heard over the lungs, but confirmation requires full investigation, especially pulmonary arteriography. This may show single localized stenoses of the pulmonary artery or main branches; hypoplasia of the pulmonary artery and/or main branches; or multiple stenoses, usually at bifurcations of the second degree or subsequent branches on each side, often with post-stenotic dilatations. The second and third patterns only were seen in the present series, none of which had the temporary infantile pulmonary artery branch stenosis described by Danilowicz et al. (1972).

Frequently there are additional cardiovascular lesions, and these commonly include those observed in 5 of the present cases.

The lesion is often mild and usually asymptomatic and nonprogressive. Its frequency may have been underestimated because the murmur may be regarded as innocent, because associated defects may confuse the diagnosis, especially without angiocardiography, and because, at necropsy, the pulmonary artery branches may not be fully examined.

In our cases sib involvement has been shown in families $M, R$, and $S$, and is most probable in $N$. Dominant inheritance seems very probable in families $M, R$, and $S$. Rubella was excluded by virological tests, and the facial features and normal intelligence did not suggest hypercalcaemia.

Association of pulmonary arterial stenosis with liver disease. The coexistence of familial pulmonary arterial stenoses and liver disease appears striking, but its significance must be assessed. If we take the frequency of congenital heart disease as $6 / 1000$ live births, of pulmonary valve stenosis as $10 \%$ of all cases of congenital heart disease, of pulmonary arterial stenoses as $10 \%$ of the cases of valvular stenosis (as is found in this centre), and familial pulmonary arterial stenoses as perhaps occurring in $25 \%$ of all families with one propositus, then the incidence of propositi with familial arterial stenoses is about 1 or 2 per 100,000 births. The incidences of neonatal hepatitis and of biliary atresia have been estimated as 
1 in 25,000 births (Paton, 1969). These figures suggest that the association of the lesions in the present families is not accidental.

The features suggest an inherited syndrome of clearly variable penetrance, with multiple manifestations, and for this we suggest the name 'arteriohepatic dysplasia'.

It is not clear how many patients have only one of the two main abnormalities. Apart from R II.2, 6 such liveborn children are noted, but they all belong to family $S$ and information about them is incomplete. 2 with liver disease died in infancy elsewhere many years ago and pulmonary arterial stenoses cannot be excluded, while the 4 noted as having only cardiovascular lesions have not undergone hepatic investigations. Unfortunately, family $S$ is now inaccessible. However, none of the 4 had any significant history.

The normal liver function tests in one clearly affected father (M I.1) could conceivably be due to complete recovery of an asymptomatic, or forgotten, neonatal hepatitis, and might not be an indication that the liver was never involved.

These considerations raise the question whether other children with pulmonary artery stenoses may have the same syndrome without overt liver involvement. However, the family history in 12 such children with nonrubella pulmonary artery hypoplasia, and liver function tests in 7 of them, have been negative.

Cardiovascular lesions in infants with obstructive jaundice. We have reviewed the notes of all other adequately documented cases admitted to the three Manchester children's hospitals in the past 10 to 20 years with diagnoses of biliary atresia and neonatal hepatitis, excluding so far as possible those with evidence of a viral aetiology. 42 cases were said to have 'neonatal hepatitis' and 32 'biliary atresia'. Systolic murmurs regarded as 'significant' were noted in 6 cases, 5 having supposed biliary atresia. 2 of these 5 children had Down's syndrome with, clinically, large septal defects. Of the others, 1 infant was recorded by a most reliable observer as having congenital heart disease with a loud systolic murmur, but necropsy at the age of 4 months revealed no cardiac lesion though the pulmonary arteries were not explored; his mother had congenital heart disease of unknown nature with a loud systolic murmur. The other 2 had undiagnosed systolic murmurs which were audible over the lungs as well as the praecordium, and both were felt to have intrahepatic biliary atresia; 1 developed hypercholesterolaemic xanthomatosis and was still alive after 11 years. Unfortunately, no further information about these families is obtainable, but the features are consistent with the present syndrome.

The child with 'neonatal hepatitis' is one of two sibs, both of whom had neonatal hepatomegaly, but no jaundice except during infections 1 and 4 years after birth. Liver biopsy in each showed extensive fatty vacuolation of liver cells. 1 of the 2 had a distant systolic murmur over the lungs, but at investigation at age 20 months pulmonary artery pressure gradients were minimal and arteriography probably normal. We feel unjustified in including these 2 children.

A review of the literature has been uninformative. Some association between congenital heart disease and biliary atresia has been long suggested, and Krovetz (1960), in reviewing 137 cases of biliary atresia reported since 1945 , found 10 cases of congenital heart disease; pulmonary arterial stenoses was not mentioned. The association would not be surprising if some of these children had Down's syndrome or trisomy 17-18, of which Alpert, Strauss, and Hirschhorn (1969) reported 7 infants with neonatal obstructive jaundice. We have not found any published report of children with familial hepatic disease and pulmonary arterial stenosis. This may be because until recently the latter was infrequently diagnosed, even at necropsy, and may perhaps have been missed more easily if an intracardiac lesion was found, to which a murmur could be ascribed. 1 of the 10 cases mentioned by Krovetz (1960) was, however, said to have idiopathic hypertrophy of the right ventricle, and this might of course have been secondary to pulmonary arterial stenoses. In a number of other cases of biliary atresia, e.g. those of Haas and Dobbs (1958), undiagnosed systolic murmurs were mentioned.

We are, however, most grateful to Dr. A. Blancquert for allowing us to report that for some years 4 unrelated children with supravalvular pulmonary artery stenoses, intrahepatic biliary atresia, and a rather odd facies have attended the Paediatric Service of the Academic Hospital in Ghent (Director: Professor Dr. C. Hooft). One of these children was reported by Vermassen and Boddaert (1962), who noted the high frequency of heart murmurs in cases of intrahepatic biliary atresia.

We feel that in the presence of severe hepatobiliary disease the significance of systolic murmurs due to pulmonary arterial stenoses may well have been overlooked in the past, and that the syndrome described in this paper may not be rare. 
Nature of liver lesions. The clinical pictures of liver involvement shown in the cases described here vary widely; some show features characteristic of 'neonatal hepatitis', others of extra- or intrahepatic biliary atresia, and others a mild chronic impairment of liver function. There is already evidence that these entities are not sharply distinguishable. Sass-Kortsak (quoted by Brent, 1962), for example, reported a child with apparent intrahepatic atresia whose sib's illness ran a course typical of neonatal hepatitis much as in family $M$ reported here. In our Case N II.3 the clinical course suggested intrahepatic biliary atresia, but biopsy showed a proliferation of interlobular ductules often taken as a sign of extrahepatic atresia (Bernstein, Braylan, and Brough, 1969; Alagille et al., 1969). However, as Harris and Andersen (1960) and Cotton (1960) have pointed out, a biopsy suggesting 'intrahepatic atresia' may be preceded by one in infancy showing an excesss of interlobular ducts, perhaps because ducts disappear if not presented with bile secretions from above. Possibly a similar process can affect the extrahepatic ducts, as in two cases of Holden (1964) where exploration and, in one, cholangiography revealed no lumen in the common bile duct, though its persistence had been shown earlier. If so, the failure in Case R II.1 to show persistent hepatic ducts may not imply a primary extrahepatic atresia. That such a state may be secondary and reversible is suggested by the several reported cases of apparent extrahepatic atresia that have recovered spontaneously.

The liver function tests showed a very variable pattern. In some there was a moderate rise in transaminases; and in some a high phosphatase, especially 5'-nucleotidase, suggesting biliary obstruction. In some the transaminase levels slowly fell, but evidence of obstruction persisted. The blood cholesterol levels were high in three, as noted by Ahrens, Harris, and MacMahon (1951) and Haas and Dobbs (1958) in 'intrahepatic atresia', but were normal or only a little raised in the other cases, though still perhaps compatible with some degree of obstruction. The normal liver histology in Case R II.3 and the absence of hyperbilirubinaemia in several cases suggest that any obstruction must be very high. It may be that the chief obstruction in our cases is not always at the same site, but nevertheless we feel that a primary defect, perhaps not uniformly distributed, in the hepatocyte-canalicular region could account for all the hepatic manifestations.

In none of our patients was giant cell change seen in liver sections, but the numbers are too small to provide a distinction from cases of 'neonatal hepatitis' where giant cells are commonly seen. In any case giant cells are not of primary significance in the diagnosis, as it seems likely that they are merely a response to injury. We feel, therefore, that our cases offer support for the view of Hays et al. (1967) that 'biliary atresia and neonatal hepatitis represent different phases of the same fundamental disease process'.

We are grateful to the many paediatricians, physicians, and pathologists who have made this report possible by referring or allowing us to see children and adults under their care, or providing us with information about them; to Dr. H. B. Marsden for his reports on liver biopsies; to Mr. A. Jolleys for details of the findings at laparotomy in 2 cases; to Dr. A. J. Barson for dissecting the lungs in Case R II.2; to Dr. R. F. Jennison for blood group studies; and to Professors J. A. Davis and H. T. Howat for helpful comment.

\section{RBFERENCES}

Ahrens, E. H., Harris, R. C., and MacMahon, H. E. (1951). Atresia of the intrahepatic bile ducts. Pediatrics, 8, 628 .

Alagille, D., Gautier, M., Habib, E. C., and Dommergues, J.-P. (1969). Les donnes de la biopsie hepatique pre- et peroperatoire. Archives Francaises de Pddiatrie, 26, 283.

Alpert, L. I., Strauss, L., and Hirschhorn, K. (1969). Neonatal hepatitis and biliary atresia associated with trisomy 17-18 syndrome. New England fournal of Medicine, 280, 16.

Bernstein, J., Braylan, R., and Brough, A. J. (1969). Bile-plug syndrome: a correctable cause of obstructive jaundice in infants. Pediatrics, 43, 273.

Brent, R. L. (1962). Persistent jaundice in infancy. Fournal of Pediatrics, 61, 111.

Cotton, D. A. (1960). Intrahepatic biliary atresia. Lancet, 2, 294.

Danilowicz, D. A., Rudolph, A. M., Hoffman, J. I. E., and Heymann, M. (1972). Physiologic pressure differences between main and branch pulmonary arteries in infants. Circulation, 45, 410.

Danks, D., and Bodian, M. (1963). A genetic study of neonatal obstructive jaundice. Archives of Disease in Childhood, 38, 378.

Haas, L., and Dobbs, R. H. (1958). Congenital absence of the intrahepatic bile ducts. Archives of Disease in Childhood, 33, 396.

Harris, R. C., and Andersen, D. H. (1960). Intrahepatic bile duct atresia. American Fournal of Diseases of Children, 100, 783.

Hays, D. M., Woolley, M. M., Snyder, W. H., Jr., Reed, G. B., Gwinn, J. L., and Landing, B. H. (1967). Diagnosis of biliary atresia: relative accuracy of percutaneous liver biopsy, open liver biopsy, and operative cholangiography. Fournal of Pediatrics, 71, 598.

Hirooka, M., and Ohno, T. (1968). A case of familial intrahepatic cholestasis. Tohoku fournal of Experimental Medicine, 84, 293.

Holden, T. M. (1964). Atresia of the extrahepatic bile duct. American Fournal of Surgery, 107, 458.

Juberg, R. C., Holland-Moritz, R. M., Henley, K. S., and Gonzalez, C. F. (1966). Familial intrahepatic cholestasis with mental and growth retardation. Pediatrics, 38, 819.

Krovetz, L. J. (1960). Congenital biliary atresia. Surgery, 47, 453, 468.

Paton, A. (1969). Liver Disease, p. 84. Heinemann, London.

Persijn, J. P., Slik, W., van der, Kramer, K., and De Ruyter, C. A. (1968). A new method for the determination of serum nucleotidase. Zeitschrift für Klinische Chemie und Klinische Biochemie, $6,441$.

Vermassen, A., and Boddaert, J. (1962). Congenitale agenesis van de intrahepatische galwegen. Maandschrift voor Kindergeneeskunde, 30, 56 .

Correspondence to Dr. G. H. Watson, Royal Manchester Children's Hospital, Pendlebury, Nr. Manchester M27 1HA. 